\title{
The Effect of a Dynamic Software on the Success of Analytical Analysis of the Circle and Prospective Mathematics Teachers Opinions
}

\author{
Enver TATAR* , Türkan Berrin KAĞIZMANLI \& Adnan AKKAYA
}

\author{
Atatürk University, Erzurum, TURKEY
}

Received: 14.01 .2013

Accepted : 25.03.2014

\begin{abstract}
The aim of the study was to examine the effects of geometry instruction, which was performed with a dynamic software, on the success of prospective elementary mathematics teachers in the analytical analysis of the circle, and to reveal their opinions in this performed geometry instruction. The embedded research design, which is among the mixed research approaches, was used in the study. The research applied 29 prospective elementary mathematics teachers and the data obtained from circle success test and semi-structured focus group interview form. In view of the analysis of the data, it was observed that the instruction, which was performed with a dynamic software, provided a positive contribution to the success of prospective teachers in the subject of the analytical analysis of the circle. Moreover, it was observed that the prospective teachers expressed that geometry instruction in a dynamic environment enabled them to understand point of power and the points on the circle, and it had positive effects on developing thinking skills, visuality, retention, learning in a short time, concretization and focusing the attention of the students with dynamism. In contrast, it was determined that the use of technology was low in mathematics and geometry courses in the secondary education institutions, and prospective teachers wanted to perform geometry instruction in dynamic environments in their teaching profession.
\end{abstract}

Key words: dynamic mathematics software, geometry instruction, analytical analysis of circle, GeoGebra, prospective teachers, analytic geometry

DOI No: 10.12973/nefmed.2014.8.1.a7

\section{Summary}

\section{Introduction}

The use of basic geometrical skills makes it possible to solve many of the problems that have to be solved by people in daily life (Altun, 2002). Through geometry, people have been

\footnotetext{
* Corresponding Author: Associate Professor Dr., Atatürk University, Kazım Karabekir Faculty of Education, Department of Secondary Science and Mathematics Education, 25240, Erzurum, TURKEY. 
able to see the undeniable realities existent in nature, to discover the relationships among these realities, and to convey these relationships to new relationships in the abstract area (mind) (Develi \& Orbay, 2003). The use of computer and computer-based cognitive tools increases in geometry instruction with advancing technology. Dynamic softwares, which are used as tools in utilizing computers in classroom environments, have induced learning environments to go beyond the ordinary by catching the attention of students and teachers. The dynamic software GeoGebra, recently used to establish the visual and dynamic interaction in mathematics instruction, fulfills the requirements that exist in dynamic environments. For instance, it is possible for students to guess the parameters of an equation of a circle by dragging the circle with the mouse and thus, GeoGebra encourages students to approach mathematics with an experimental method (Hohenwarter \& Fuchs, 2004). When conducted studies are examined, the effects of the use of the pieces of dynamic software in geometry instruction are observed in student success and forming geometrical knowledge by the students. On the other hand, it is an interesting fact that the diversity of the geometry subjects addressed in existing research is low. Therefore, whether instruction in dynamic environments succeeds in every subject of geometry is a subject that must be researched. It is that that the studies conducted in the field will contribute to teaching geometry in the best way.

The aim of the study was to examine the effects of geometry instruction, which was performed with a dynamic software, on the success of prospective elementary mathematics teachers in the analytical analysis of the circle, and to reveal their opinions in this performed geometry instruction.

\section{Methodology}

The embedded research design, which is among the mixed research approaches, was used in the study. The quantitative section of the research was designed as a single-group pretest/post-test method, whereas the qualitative section of the research was designed as a case study. Circle success test (Appendix 1), which was implemented as pre-test/post-test in the subject of the analytical analysis of the circle, and semi-structured focus group interview form (Appendix 2) were used in the study as data collection tools. In the research process, GeoGebra software was used, dynamic materials and study sheets were prepared in the subject of the analytical analysis of the circle. The materials and the study sheets were formed by the writers of this research for the purpose of teaching the following concepts: 'circle equation', 'tangent equation that is drawn from a point on the circle', 'the equations of the tangents that are drawn towards a circle from a point outside of it', 'the states of the line and 
the circle to each other', 'the power of the point in relation with the circle' and 'the positions of the circles to each other'. SPSS 16.0 package program was used for the analysis of the data that was obtained from the circle success test in which the quantitative data of the research was obtained. Normality analysis of the data was conducted in order to determine the test that would be used in analyzing the data. Accordingly, the data was analyzed using the Wilcoxon Test. Content analysis and descriptive analysis were used in evaluating the qualitative data of the research.

\section{Results}

In view of the analysis of the data that was obtained from the research, it was observed that the instruction, which was performed with a dynamic software, provided a positive contribution to the success of prospective teachers in the subject of the analytical analysis of the circle. Moreover, it was observed that the prospective teachers expressed that geometry instruction in a dynamic environment enabled them to understand point of power and the points on the circle, and it had positive effects on developing thinking skills, visuality, retention, learning in a short time, concretization and focusing the attention of the students with dynamism. In contrast, it was determined that the use of technology was low in mathematics and geometry courses in the secondary education institutions, and prospective teachers wanted to perform geometry instruction in dynamic environments in their teaching profession. In view of the results obtained in the research, it is imperative that dynamic environments are formed, that teachers continue to conduct their courses in these dynamic environments and that dynamic instruction materials are developed for various geometry subjects. 


\title{
Dinamik Bir Yazılımın Çemberin Analitik İncelenmesinde Başarıya Etkisi ve Matematik Öğretmeni Adaylarının Görüşleri
}

\author{
Enver TATAR ${ }^{\dagger}$, Türkan Berrin KAĞIZMANLI ve Adnan AKKAYA \\ Atatürk Üniversitesi, Erzurum, TÜRKİYE
}

Makale Gönderme Tarihi: 14.01.2013

Makale Kabul Tarihi: 25.03.2014

\begin{abstract}
Özet - Bu araştırma, dinamik bir yazılım kullanılarak yapılan geometri öğretiminin ilköğretim matematik ögretmeni adaylarının, çemberin analitik incelenmesi konusundaki başarılarına etkisini incelemek ve yapılan geometri öğretimine ilişkin görüşlerini ortaya çıkarmak amacıyla yapılmıştır. Araştırmada karma araştırma yaklaşımlarından biri olan gömülü desen kullanılmıştır. 29 ilköğretim matematik öğretmeni adayına uygulanan bu araştırmada veriler, başarı testi ve odak grup görüşmesinden elde edilmiş̧ir. Elde edilen verilerin analizi sonucunda, dinamik ortamda yapılan öğretimin, çemberin analitik incelenmesi konusunda öğretmen adaylarının başarılarına olumlu yönde katkı sağladığı tespit edilmiştir. Ayrıca öğretmen adaylarının, dinamikliğin; kuvvet noktasının ve çember üzerindeki noktaların anlaşılmasını sağladığını belirttikleri ve dinamik ortamda geometri öğretiminin düşünme becerilerini geliştirme, görsellik, kalıcı öğrenme, kısa sürede öğrenme, somutlaştırma ve öğrencinin dikkatini toplaması üzerine olumlu etkisinin olduğunu söyledikleri görülmüştür. Öğretmen adaylarının öğrenim gördükleri liselerde matematik ve geometri derslerinde teknoloji kullanımının az olduğunu ifade ettikleri ve öğretmenlik yaşamlarında dinamik ortamlarda geometri öğretimi yapmak istedikleri belirlenmiştir.
\end{abstract}

Anahtar kelimeler: dinamik matematik yazılımı, geometri öğretimi, çemberin analitik incelenmesi, GeoGebra, öğretmen adayları, analitik geometri

\section{DOI No: 10.12973/nefmed.2014.8.1.a7}

\section{Giriș}

Günlük yaşamda insanların çözmek zorunda kaldıkları problemlerin birçoğunun çözümü temel geometrik beceriler kullanımı ile mümkün olmaktadır (Altun, 2002). İnsanın geometri adına yaptığı, doğada var ve yadsınamaz gerçekleri görmek, bunlar arasındaki ilişkileri keşfederek soyut alanda (zihinde) bu ilişkileri yeni ilişkilere götürmek olmuştur

\footnotetext{
† İletişim: Doç. Dr., Atatürk Üniversitesi, Kazım Karabekir Eğitim Fakültesi, Ortaöğretim Fen ve Matematik Alanları Eğitimi Bölümü, 25240, Erzurum, TÜRKIYE.

E-mail: entatar@gmail.com
} 
(Develi \& Orbay, 2003). Geometri öğrenme alanında yer alan konular, öğrencilerin nesnel ve eleştirel düşünme, neden sonuç ilişkilerini kurabilme ve sayısal düşünme becerilerini geliştirmede önemli rol oynamaktadır (Oral \& İlhan, 2012). NCTM (National Council of Teachers of Mathematics), geometrinin; öğrencilerin görselleştirmeyi, uzamsal düşünmeyi ve problemlerin çözümünde geometrik modellemeleri kullanarak geometrik şekillerin özelliklerini analiz etmelerini ve geometrik ilişkilerin matematiksel olarak ifade edilebilmesini sağlayacağını belirtmektedir. Buna bağlı olarak, öğrencilerin muhakeme ve gerekçelendirme becerilerini geliştirmenin matematiğin doğal bir alanı olan geometri ile mümkün olacağı vurgulanmıştır (NCTM, 2000). Geometri öğrenimi, çocukların çevrelerindeki fiziksel dünyayı görmeye, bilmeye ve anlamaya başlamaları ile başlar ve tümevarımlı veya tümdengelimli sisteminin içinde gelişen yüksek düzeyde geometrik düşünme ile devam eder (Ubuz, 1999). Geometrik düşünme becerilerinin gelişimi, günlük hayat problemlerinin çözümünün yanında bu çözümlere mantıksal açıklamalar yapabilmeyi ve olaylar arasındaki ilişkileri sorgulayabilmeyi sağlar. Buna göre geometri alanının amacı, düzlemde ve uzayda geometrik nesnelerin özelliklerini tanıma, aralarındaki ilişkileri bulma, geometrik yeri tanımlama, dönüşümleri açıklama ve ifade etme, geometrik önermeleri kanitlama olarak belirtilebilir (Baki, 2006).

Teknolojinin ilerlemesiyle birlikte geometri öğretiminde bilgisayar ve bilgisayara dayalı bilişsel araçların kullanımı artmaktadır. Bilgisayarların sınıf ortamlarında kullanılmasında araç olarak kullanılan dinamik yazılımlar, öğrencilerin ve öğretmenlerin ilgisini çekerek öğrenme ortamlarının alışılmışın dışına çıkmasına neden olmuştur. Kağıt üzerinde yapılan cetvel ve pergel çizimleriyle karşılaştırıldığında; doğru çizim yapabilmeyi (keşisme noktaları, teğet, vb) ve kullanıcının değerlerini her zaman değiştirebildiği geometrik kavramları inşa edebilmeyi sağlamaktadır (Freixas, Joan-Arinyo \& Soto-Riera, 2010). Özellikle geometrik bilginin geleneksel tümdengelimli mantık ve dilsel tabanlı temsili yeniden yorumlanabilmekte veya tanımlanabilmektedir (Lopez-Real \& Leung, 2006). Böylelikle öğrencilere, geometrik ilişkileri araştırabilecekleri ve yapıları oluşturup test edebilecekleri bir ortam sağlanmaktadır (Güven \& Kösa, 2008).

Dinamik yazılımların şekilleri sürükleme ve görselleştirme özelliği, geometrik problemlerin zihinde somutlaştırılmasında güçlü bir araç olarak karşımıza çıkmaktadır. Örneğin dinamik çizimi yapılan bir karenin elemanlarını sürükleyerek birçok karenin çiziminin inşasını bir bütün olarak görme imkanını sunar (Sinclair \& Yurita, 2008). Bu sayede geometrik kavramların grafiksel gösterimleri ve inşası daha etkili olmaktadır (Kokol-Voljc, 
2007). Ayrıca oluşturulan şekil ve nesnelerin farklı özellikleri arasındaki ilişkiler hakkında varsayım yapabilmeyi sağlar (Wares, 2010). Son zamanlarda matematik öğretiminde görsel ve dinamik etkileşimi sağlamak amacıyla kullanılan GeoGebra yazılımı, dinamik ortamlarda var olan gereksinimleri karşılamaktadır. Bu yazılımın, nesneleri dinamik olarak sürükleme ve görselleştirme özelliği, matematikte var olan çoklu problem durumlarına hakim olmayı ve böylelikle problemlerin somutlaştırılmasını sağlamaktadır (Tatar, Akkaya \& Kağızmanlı, 2011). Öğretmenler ders işlerken dinamik şekilleri oluşturabilmektedirler ve bu onlara öğrencilerin sorularına ve önerilerine tepki verecekleri esnek bir öğretme stilini sağlamaktadır (Hohenwarter, Hohenwarter, Kreis, \& Lavicza, 2008). Öğrencilerin fareyle çemberi sürükleyerek bir çember denkleminin parametrelerini tahmin etmeleri mümkündür, böylelikle GeoGebra matematiğe deneysel bir yolla yaklaşmaları için öğrencileri teşvik etmektedir (Hohenwarter \& Fuchs, 2004). Ismail (2009)' a göre GeoGebra, öğrencilerin sinıf tartışmalarında ortaya çıkan çeşitli matematiksel konuları ve örnekleri sürekli gözlem ve tekrarlarla görmelerini ve çizim yapmalarını mümkün kılmaktadır. Bunun için dünyanın birçok yerinde öğretmenler GeoGebra ile dinamik çalışma yaprakları ve materyaller hazırlayarak öğrencilerine işlemsel ve kavramsal bilginin bir arada olduğu öğrenme ortamlarını sunmaktadırlar.

Araştırmalarda dinamik yazılımlar kullanılarak yapılan geometri öğretiminin öğrenci başarılarına ve geometri öğrenmelerine etkisinin incelendiği görülmektedir (Biza \& Zachariades, 2008; Bretscher, 2009; Carter \& Ferrucci, 2009; Erbas \& Yenmez, 2011; Fahlberg-Stojanovska \& Trifunov, 2010; Gardiner, Hudson \& Povey, 2000; Güven \& Karataş, 2003; Güven \& Karataş, 2005; Güven \& Kösa, 2008; Hangül \& Üzel, 2010; Kösa \& Karakuş, 2010; Köse \& Özdaş, 2009; Selçik \& Bilgici, 2011; Sinclair \& Yurita, 2008; Olivero, 2001). Dinamik yazılımlar kullanılarak yapılan araştırmalara bakıldığında; FahlbergStojanovska ve Trifunov (2010) iki gruptan oluşan öğrencilerin projelerini incelemişlerdir. Bir grup öğrencinin yapım aşamasında klasik yolları diğer grubunda GeoGebra'yı kullandıkları sınıf çalışmalarında, GeoGebra’yı kullanan gruptaki öğrencilerin daha başarılı olduklarını belirlemişlerdir. Selçik ve Bilgici (2011) çokgenler konusunun öğretimini iki farklı yolla yapmışlardır. Bir grup ilköğretim öğrencisine GeoGebra yazılımı kullanarak hazırladıkları çalışma yaprakları (worksheets) ile, diğer bir gruba ise klasik yollarla öğretim yapmışlardır. GeoGebra ile yapılan öğretimin daha başarılı olduğu sonucuna varmışlardır. Mainali ve Key (2012) dinamik ortamda geometrinin anlatıldığı bir çalıştaya (workshop) ilişkin öğretmen ve öğrencilerin çok etkilendiklerini ve GeoGebra'yı matematik öğrenmek için etkili bir araç olarak nitelediklerini belirlemişlerdir. Güven ve Kösa (2008) dinamik 
geometri yazılımı Cabri 3D’nin matematik öğretmeni adaylarının uzamsal becerileri üzerindeki etkisini incelemişlerdir. Cabri 3D’nin matematik öğretmeni adaylarının uzamsal becerileri üzerinde pozitif etkisi olduğu belirlenmiştir. Dinamik ortamların geometri öğrenmeye etkisini inceleyen araştırmaların öğrencilerin geometrik düşünme becerileri üzerinde durduğu görülmektedir. Yapılan bir araştırmada Carter ve Ferrucci (2009) GeoGebra'nın öğretmen adaylarının geometriyi anlamaları üzerindeki etkisini araştırmışlar ve GeoGebra'nın geometri anlamayı yükselttiğini belirlemişlerdir. Güven ve Karataş (2003) çalışmalarında öğrencilerin Cabri ortamında gördükleri geometrinin bir keşfetme aktivitesi olduğunu düşündüklerini belirlemişlerdir. Kösa ve Karakuş (2010) analitik geometri öğretiminde Cabri 3D’nin kullanımını araştırdıkları çalışmalarında; matematik öğretmeni adayları, yazılımın 3-boyutlu geometri öğreniminde görselleştirme sağladığı için kullanışlı olduğunu belirtmişler ve Cabri 3-D yazılımını kullanarak konuyla ilgili problemlerin çözümünü yapabildiklerini ifade etmişlerdir. Güven ve Karataş (2005) ilköğretim öğrencilerinin Pisagor Teoreminin Cabri yazılımı ile keşfini incelemişlerdir ve böyle öğrenme ortamlarının, öğrencilerin öğrenme ürünlerine ve bilgi kurma süreçlerine faydalı olduğu sonucuna varmışlardır. Özdemir ve Tabuk (2004) bilgisayar destekli öğretimin öğrencilerin çember, daire ve silindir konusunu öğrenmelerinde etkili olduğunu ve öğrenci başarısını artırdığını tespit etmişlerdir. Köse ve Özdaş (2009) ise ilköğretim öğrencileriyle yaptıkları çalışmalarında; simetri kavramının kazandırılmasında ve temel özelliklerinin öğrenciler tarafından belirlenmesinde Cabri geometri programının güçlü bir araç olduğunu belirlemişlerdir.

Formal eğitimde sınıf düzeyleri arttıkça matematiksel kavramların soyutluk, karmaşıklık ve hiyerarşiklik düzeyleri artmaktadır (Çetin, Dane \& Bekdemir, 2012). Matematik öğretiminde matematiksel yazılımların uygun kullanımının matematiğin öğretilmesini ve öğrenilmesini büyük oranda desteklemesinden dolayı bugünün matematik ve fen öğretmenlerinin ve öğretmen adaylarının öğretimde teknolojinin kullanılması konusunda hazırlanması öne çıkmaktadır (Kokol-Voljc, 2007). Yapılan araştırmalar incelendiğinde dinamik yazılımların geometri öğretiminde kullanılmasının öğrenci başarıları ve öğrencilerin geometri bilgisi oluşturmaları üzerindeki etkileri görülmektedir. Bununla birlikte araştırmalarda ele alınan geometri konularının çeşitliliğinin az olması dikkat çekicidir. $\mathrm{Bu}$ nedenle dinamik ortamlarda öğretimin geometrinin her konusunda başarı sağlayıp sağlamayacağı araştırılması gereken bir konudur. $\mathrm{Bu}$ anlamda yapılacak çalışmaların geometrinin en iyi şekilde öğretilmesine fayda sağlayacağı düşünülmektedir. Araştırma 
geometrinin temel konularından olan çemberin analitik incelenmesi konusunun dinamik ortamlarda öğretimine ilişkin bulgular vereceğinden, dinamik matematik eğitimi uygulamalarının planlanmasında ve uygulamasında katkı sağlayacağı düşünülmektedir. Bu noktada öğretmen adaylarının böyle öğrenme ortamları ile ilgili neler düşündüklerini belirlemek önemlidir. Araştırmada, dinamik bir yazılım kullanılarak yapılan geometri öğretiminin ilköğretim matematik öğretmeni adaylarının, çemberin analitik incelenmesi konusundaki başarılarına etkisini incelemek ve yapılan bu geometri öğretimine ilişkin görüşlerini ortaya çıkarmak amaçlanmıştır.

\section{Yöntem}

Araştırmada karma araştırma yaklaşımlarından biri olan gömülü desen kullanılmıştır. Gömülü desende araştırmacı, aynı anda veya sırayla nicel ve nitel verileri toplar ve elde ettiği nicel ve nitel verileri birinin diğerini destekleyecek şekilde açıklar. Destekleyici olan veriler nicel ya da nitel veriler olabilir fakat alan yazında genellikle nitel verilerin nicel verileri desteklediği görülmektedir (Creswell, 2011).

Araştırmanın nicel kısmı deneysel desen olan tek grup ön test-son test yöntemi olarak desenlenmiştir. Bu yöntemde bir gruba ön test verilir sonra deneysel işlem yapılır ve sonrada son test verilir. Ön test ve son test farklı zamanlarda verilen aynı testlerdir ve uygulama ile ön testten son teste kadar olan değişim incelenir (McMillan \& Schumacher, 2010). Araştırmanın nitel kısmı durum çalışması olarak desenlenmiştir. Durum çalışmasında ele alınan durum; bir program, bir olay, bir aktivite veya zaman ve yer ile sınırlandırılmış bireyler olabilir (McMillan \& Schumacher, 2010). Ayrıca durum çalışmasında araştırmacılar bilgiyi doğrudan kaynaktan almak isterler ve çalıştıkları ortam, katılımcılar ya da dokümanla doğrudan ilişki içinde bulunurlar (Büyüköztürk, Çakmak, Akgün, Karadeniz \& Demirel, 2010).

\subsection{Katılımcllar}

Araştırma Türkiye'de bulunan bir üniversitenin eğitim fakültesinde öğrenim gören 29 ilköğretim matematik öğretmeni adayıyla gerçekleştirilmiştir. Araştırmanın sonunda gönüllü 8 öğretmen adayıyla odak grup görüşmesi yapılmıştır.

\subsection{Veri Toplama Aracl}

Araştırmada veri toplama aracı olarak, çemberin analitik incelenmesi konusunda ön test-son test şeklinde uygulanan çember başarı testi (Ek 1) ve yarı yapılandırılmış odak grup görüşme formu kullanılmıştır (Ek 2). Başarı testi bu araştırmanın yazarları tarafından geliştirilmiştir. Başarı testinin konu ile ilgili kapsam geçerliliğinin olmasına dikkat edilmiştir. 
Bunun için test maddelerinin oluşturulması sırasında alanında uzman iki matematik eğitimcisinin görüşlerine başvurulmuş ve maddeler yeniden düzenlenmiştir. Başarı testi 9 açık uçlu maddeden oluşmuştur. Test 30 dakika içinde cevaplanacak şekilde hazırlanmıştır. Başarı testinin Cronbach $\alpha$ - güvenirlik katsayısı 0.786 olarak hesaplanmıştır. Araştırmada yarı yapılandırılmış odak grup görüşme yapılarak, planlanmış bir yönerge çerçevesindeki sorulara ve görüşme sırasında ortaya çıkan sorulara cevap bulmak amaçlanmıştır. Örneklem büyüklüğünün yanı sıra odak grup görüşmeleri doğası gereği etkileşimli süreçlerdir (Yıldırım \& Şimşek, 2011). Yarı yapılandırılmış odak grup görüşme soruları bu araştırmanın yazarları tarafından önceden hazırlanarak uzman görüşüne sunulmuş ve sorular yeniden düzenlenmiştir.

\subsection{Materyallerin ve Çalışma Yapraklarının Geliştirilmesi}

Araştırma sürecinde GeoGebra yazılımı kullanılarak çemberin analitik incelenmesi konusunun kazanımlarına uygun biçimde dinamik materyaller ve çalışma yaprakları hazırlanmıştır. Materyaller ve çalışma yaprakları 'çember denklemi', 'çemberin üzerindeki bir noktadan çizilen teğet denklemi', 'bir çembere dişındaki bir noktadan çizilen teğetlerin denklemleri', 'doğru ile çemberin birbirine göre durumları', 'bir noktanın bir çembere göre kuvveti' ve 'çemberlerin birbirlerine göre konumları' kavramlarının öğretilmesi amacıyla bu araştırmanın yazarları tarafından oluşturulmuştur. Materyallerin ve çalışma yapraklarının çemberin analitik incelenmesi konusunun öğretiminde kullanılabilirliğgi ile ilgili olarak matematik eğitimi üzerine araştırma yapan 2 uzman görüşüne başvurulmuş ve elde edilen dönütler doğrultusunda gerekli değişiklikler yapılmıştır. Materyal ve çalışma yapraklarından örnekler Ek 3 ve Ek 4’te sunulmuştur.

\subsection{Araştırmanın Uygulanması}

Araştırmanın ilk aşamasında deneysel işlem öncesinde, öğretmen adaylarına çember başarı testi ön test olarak uygulanmıştır. Uygulama bilgisayar laboratuvarında haftada dört ders saati olmak üzere iki haftalık bir sürede araştırmanın ikinci yazarı tarafından yürütülmüştür. Her öğretmen adayının bir bilgisayar kullanarak dersi takip etmesi sağlanmıştır. Bunun için öncelikle GeoGebra yazılımı ve hazırlanan materyaller bilgisayarlara yüklenmiştir. Uygulama kapsamında öncelikle öğretmen adaylarına iki ders saati boyunca GeoGebra yazılımı tanıtılmış ve öğrencilerin en çok kullanacakları menüler gösterilmiştir. Daha sonra öğretmen adaylarına beş ders saati boyunca dinamik öğrenme ortamında çemberin analitik incelenmesi konusu anlatılmıştır. $\mathrm{Bu}$ süreçte konu ile ilgili hazırlanan dinamik materyaller ve çalışma yaprakları kullanılmıştır. Öğretmen adaylarının materyalleri ve her bir 
materyalle ilgili olan çalışma yapraklarını kullanmaları sağlanmıştır. Buna göre öğretmen adaylarının çalışma yapraklarındaki genellemelere kendilerinin varmaları için bir süre beklenmiş ve bu süre sonunda varılan genelleme sınıfta paylaşılmıştır. Araştırmacılar gerekli yerlerde öğretmen adaylarına rehberlik etmiştir. Uygulamalar sırasında öğretmen adaylarının kendi öğrenmelerini oluşturabilecekleri dinamik bir öğrenme ortamı oluşturulmuş ve derse aktif katılımları gözlenmiştir. Deneysel işlem sonunda, öğretmen adaylarına çember başarı testi son test olarak uygulanmıştır.

Araştırmanın son aşamasında gönüllü 8 öğretmen adayı ile yarı-yapılandırılmış odak grup görüşmesi yapılmış, konuyla ilgili görüşleri belirlenmiştir. Görüşme sırasında ses kayıt cihazı kullanılması ile ilgili olarak gerekli izinler öğretmen adaylarından alınmıştır. Odak grup görüşmesi toplam 37 dakika sürmüştür.

\subsection{Verilerin Analizi}

Araştırmanın nicel verilerinin elde edildiği başarı testinde yer alan açık uçlu 9 maddenin değerlendirilmesi; doğru, kısmen doğru ve yanlış düzeylerine göre yapılmıştır. Doğru yanıt için "2", kısmen doğru yanıt için "1" ve yanlış yanıt için “0” puan verilmiştir. En yüksek puan 18, en düşük puan 0 olarak belirlenmiştir. Maddelerin değerlendirilmesinde araştırmacıların hemfikir olmasına dikkat edilmiştir. Başarı testinden elde edilen verilerin analizleri için SPSS 16.0 paket programı kullanılmıştır. Verilerin analiz edilmesinde kullanılacak testi belirlemek amacıyla öncelikle verilerin normallik analizi yapılmıştır. Örneklem sayısı 29 olduğundan normallik analizi için Kolmogorov-Smirnov testi kullanılmıştır (Kalaycı, 2009). KolmogorovSmirnov testi sonuçları göz önüne alınarak başarı puanlarının istatistiksel analizinde nonparametrik testlerden yararlanılmıştır. Buna göre veriler Wilcoxon Testi kullanılarak analiz edilmiştir. Anlamlılık düzeyi olarak $\alpha=0,05$ seçilmiştir.

Araştırmanın nitel verilerinin değerlendirilmesinde içerik ve betimsel analiz kullanılmıştır. İlk önce öğretmen adaylarıyla yapılan odak grup görüşmesi transkript edilmiştir. Elde edilen verilerin içerik analizi için veriler okunmuştur ve ilk kodlar tanımlanmıştır. Ardından her öğretmen adayının verdikleri cevaplar yeniden okunarak kodlar düzenlenmiştir. $\mathrm{Bu}$ işlem birkaç kez tekrar etmiş, son olarak elde edilen benzer kodlar kategoriler altında birleştirilmiş ve bulunan bu kodlar sunulmuştur. Birden fazla öğretmen adayının üzerinde durduğu kodlar bir yıldız işareti ile belirtilmiştir. Verilerin betimsel analizi için odak grup görüşmesine katılan ve $\mathrm{B}_{1}$ den $\mathrm{B}_{8}$ 'e kadar kodlanan öğretmen adaylarından örnek alıntılara yer verilmiştir. 


\section{Bulgular}

$\mathrm{Bu}$ bölümde araştırma problemine ilişkin bulgular ele alınmakta ve sırasıyla deneysel bulgular ve nitel bulgular ile ilgili yorumlara yer verilmektedir.

\subsection{Deneysel Bulgular}

Çemberin analitik incelenmesinin öğretiminin dinamik ortamda yapılmasında matematik öğretmeni adaylarının başarıları açısından deneysel işlem öncesi ve deneysel işlem sonrası arasında anlamlı bir fark olup olmadığına ilişskin veriler analiz edilerek elde edilen bulgular sunulmuştur.

Araştırmadan elde edilen ön test ve son test verilerinin normal dağılıma uygunluğu Kolmogorov-Smirnov normallik testi ile incelenmiştir. Buna göre elde edilen p değerleri incelendiğinde; uygulama grubunun ön test $(\mathrm{p}=.010)$ puanlarının dağ 1 lımının normal dağılıma uygun olmadığı $(\mathrm{p}<.05)$, son test $(\mathrm{p}=.200)$ puanlarının dağılımının normal dağılıma uygun olduğu görülmüştür ( $\mathrm{p}>$.05). Araştırmadan elde edilen ön test ve son test başarı puanları arasında fark olup olmadığını belirlemek için kullanılan Wilcoxon Testi sonuçları Tablo1'de sunulmuştur.

Tablo 1 Öğretmen Adaylarının Ön Test Son Test Başarı Puanlarının Wilcoxon Testi Sonuçları

\begin{tabular}{llllll}
\hline Son Test- Ön Test & N & Sira Ortalaması & Sıra Toplamı & $\mathbf{z}$ & $\mathbf{p}$ \\
\hline Negatif Sıra & 1 & 1,00 & 1,00 & $4,69^{*}$ &, 000 \\
Pozitif Sıra & 28 & 15,50 & 434,00 & & \\
Eşit & 0 & & & & \\
\hline
\end{tabular}

* Negatif Siralar Temeline Dayalı

Tablo 1 incelendiğinde uygulama grubu öğrencilerinin ön test ile son test puanları arasında anlamlı bir farklılık bulunmaktadır $(\mathrm{z}=4,691, \mathrm{p}<.05)$. Fark puanlarının sira toplamına bakıldığında, gözlenen farkın son test lehinde olduğu görülmektedir. Buna göre, yapılan öğretimin, çemberin analitik incelenmesi konusunda matematik öğretmeni adaylarının matematik başarılarını olumlu etkilediği söylenebilir.

\subsection{Nitel Bulgular}

Araştırmadan elde edilen nitel veriler, "öğretmen adaylarının çemberin analitiğinin dinamik öğretimi üzerine görüşleri”, "lise matematik ve geometri derslerinde teknoloji kullanımı” ve "öğretmen adaylarının öğretmenlik yaşamlarında dinamik ortamlarda geometri öğretimi yapma hakkındaki görüşleri” şeklinde üç alt başlık altında incelenecektir. 


\subsection{1. Öğretmen Adaylarının Çemberin Analitiğinin Dinamik Öğretimi Üzerine Görüşleri}

Öğretmen adaylarının odak grup görüşmesinde, 'Yapılan çemberin analitiğinin dinamik öğretimi hakkında ne düşünüyorsunuz?' sorusuna verdikleri cevaplar analiz edilerek elde edilen bulgular kategori ve kodlar halinde Tablo 2’ de verilmiştir.

Tablo 2 Öğretmen Adaylarının Çemberin Analitiğinin Dinamik Öğretimi Üzerine Görüşleri

\begin{tabular}{ll}
\hline Kategori & Kod \\
\hline İçerik & Açıların gerçek değerlerinde gözükmesi \\
& Çembere ait kavramların (teğet, kiriş, kuvvet noktası,...) algılanması \\
& Çember üzerindeki noktaların anlaşılmasını sağlar* \\
& Dinamiklik, kuvvet noktasının anlaşıllmasını sağlar* \\
& Nokta ve doğruların çember üzerindeki ilişkisi belirlenir \\
& Bilginin ezberlenmesini önler \\
& Bilgilerin anlamlı ilişkilerini öğrenme \\
& Düşünme becerilerini geliştirme* \\
& Görerek öğrenme \\
& Görsellik* \\
& Kalıcı öğrenme* \\
& Kısa sürede öğrenme* \\
& Kolay öğrenme \\
& Somutlaştırma* \\
& Lisede uygulanmalıdır \\
& Öğrencinin dikkatini toplar* \\
& Öğrencinin ilgisini çeker \\
& Öğretmenin dersten önce araştırma yapmasını sağlar \\
& Öğretmenin kendini geliştirmesini sağlar \\
\hline Öğretim &
\end{tabular}

Yapılan odak grup görüşmesinde öğretmen adaylarının bu konu üzerinde farklı görüşler belirterek, tartışmalar yaptıkları gözlenmiştir.

Öğretmen adaylarından $B_{7}$, çemberin analitiğinin dinamik öğretiminde görselliğin önemli olduğunu ve kalıcı öğrenmeler sağlayacağını şu ifadeler ile belirtmiştir;

“Bu konuyu ögrrenirken görsellik çok önemlidir. Onu da bu uygulamada görmüş olduk.

Görsellik konuda verilen bilgilerin beyinde daha kalıcı olmasını sağllyor. Bu da ögrenilen bilginin \%70-80 oranında daha çok beyinde durmasını sağlayarak konunun daha geç unutulmasına da olanak sağllyor. Bu şekilde bu uygulamanın iyi bir uygulama olduğunu düşünüyorum." 
Öğretmen adayı $B_{8}$ yapılan uygulamada nokta ve doğruların çember üzerindeki ilişkisi belirlendiğini ve çembere ait kavramların algılandığını;

"Bu uygulamada dikkatimi çeken klsım kağıt üzerinde tek boyutlu olarak noktaları biliyoruz. Ama bu programda noktalarl değiştirerek doğruların ne taraftan geçtiğini veya çemberin ne taraftan geçtiğini görebiliyoruz. Mesela teğet meselesi, çizgileri doğru düzgün kağıt üzerinde nerden çekeceğimi bilemiyorum. Ama GeoGebra programında teğetin kayma seviyesini, farklılıkları görebiliyorum. Çözerken daha rahat oluyorum. Yani çok istekli olarak derse katılmamı sağladı."

sözleri ile ifade etmiştir.

Öğretmen adaylarından $B_{5}$, açıların gerçek değerlerinde gözükmesinin görsellik açısından önemli olduğunu şu şekilde ifade etmiştir;

"Bence şöyle bir güzelliği de var ayrıca. Bir geometri dersinde soru çözülürken mesela 40 derecelik açıyı biz tahtaya çizdiğimizde, açı 40 derecelik açı gibi görünmeyebilir. Öyle çizimler oluyor ki hoca diyor ki bize 'burası aslında 30 derece ama siz daha büyük falan görmeyin'. Yani öyle bir göz yanılması olabilir ama bu program sayesinde her açıyı gerçek derecesinde görebiliyoruz. Bu da görsel açıdan güzel bir yol sağlayabilir."

Öğretmen adayı $\mathrm{B}_{4}$, çember üzerinde değişen değerlerin anlaşıldığını ve çemberin analitiğinin dinamik öğretiminin lisede uygulanması gerektiğini;

"Bence özellikle lise eğitiminde ögrencilere verilmesi gerektiğini düşünüyorum. Bir soruyu çözerken, aynı soruda değerler değiştikçe çember üzerinde değerlerin değiştiğini de görmek, yani o görsellik matematikte çok önemli. Yani bu üniversitede değilde daha çok temelden verilmesi gereken bir eğitim diye düşünüyorum." sözleri ile dile getirmiştir.

Öğretmen adayı $B_{1}$ ise uygulamanın bilginin ezberlenmesini önlediğini belirterek şöyle söylemiştir;

"Bence ezberci ĕgitimin zıddı bir uygulamaydı. Bir soruyu farklı şekillerde farklı uygulamalarla tekrar tekrar ve görsel olarak gördüğümüz için mantı̆̆ını kavradık.”

\subsubsection{Lise Matematik ve Geometri Derslerinde Teknoloji Kullanımı}

Öğretmen adaylarının odak grup görüşmesi sırasında ortaya çıkan 'Lise matematik ve geometri derslerinizde teknoloji kullanıldı mı?' sorusuna verdikleri cevaplar analiz edilerek elde edilen bulgular Tablo 3'de sunulmuştur. Öğretmen adaylarının cevapları incelendiğinde 5 öğretmen adayının matematik derslerinde teknoloji kullanılmadığını, 6 öğretmen adayının da 
geometri derslerinde teknoloji kullanılmadığını belirttikleri görülmüştür. Öğretmen adaylarının konu ile ilgili görüşleri şu şekildedir;

Öğretmen adaylarından $B_{3}$, matematik ve geometri derslerinde teknoloji kullanıldığını;

"Biz matematik dersinde de geometri dersinde de kullanmıştık. Matematikte bir testi hoca yansitıyordu oradan çabuk çabuk soruları çözüyorduk. Zamandan tasarruf ediyorduk. Geometride ise 3. boyutu görebilmek için hoca yansıtarak gösteriyordu. Çok faydası oluyordu, biz hayal edebiliyorduk, nasıl olduğunu düşünebiliyorduk." sözleriyle ifade etmiştir.

Öğretmen adaylarından $\mathrm{B}_{4}$, matematik ve geometri derslerinde teknoloji kullanılmadığını söylemiştir. $\mathrm{B}_{4}$;

"Benim okuduğum okulda matematik ve geometri derslerinde hiç kullanıldı̆̆ını görmedim. Kendi sınıfimda diğer sinıflarda dahil. Biz trigonometriyi öğreniyoruz ya da ben çemberi öğreniyorum ama nerede kullaniyorlar? Çok merak ettiğim şeyler olurdu ama hiç ögrenemedim. Bunlar hep cevapsız sorular oldu."

Öğretmen adaylarından $\mathrm{B}_{5}$, matematik ve geometri derslerinde teknoloji kullanıldığını şu şekilde ifade etmiştir;

"Bizin derslerimizde şöyle kullanılıyordu; geometri derslerinde, soruları biz çizmeyelim diye tahtadan yansitıllyordu ve tahtada çözüm yapıyorduk. Matematik derslerinde de sadece soru tekrarlarını tahtada slayt şeklinde görüyorduk."

\subsection{3. Öğretmen Adaylarının Öğretmenlik Yaşamlarında Dinamik Ortamda Geometri} Öğretimi Yapma Hakkındaki Görüşleri

Öğretmen adaylarına 'Öğretmen olduğunuzda dinamik bir ortamda geometri öğretimi yapmayı düşünür müsünüz? Neden?' sorusu yöneltilmiştir. Buna göre öğretmen adaylarının tamamının öğretmenlik yaşamlarında dinamik ortamda ders yapmayı düşündükleri belirlenmiştir. Sadece bir öğretmen adayının dinamik ortamlarda geometri öğretimini bazen yapmak istediğini belirttiği görülmüştür. Öğretmen adaylarının konu ile ilgili görüşleri şu şekildedir;

Öğretmen adaylarından $B_{2}$ öğretmenlik yaşamında bu uygulamayı yapacağını ve dinamikliği kullanarak farklı örnekleri çözebileceğini belirtmiştir. $\mathrm{B}_{2}$ 'nin ifadesi şöyledir;

“Kullanmayı düşünürüm. Çünkü öğretmen olduğumda işimi kolaylaştırır. Mesela konu ile ilgili bir soru çözdük. O sorunun değerleri değiştiğinde, öğrencinin o değerler değiştiğinde o şeklin, o görüntünün değiştiğini görmesi onların aklında daha çok yer tutar ve öğrencinin daha iyi anlamasını să̆lar diye düşünüyorum." 
Öğretmen adaylarından $B_{6}$ öğretmenlik yaşamında dinamik ortamlarda ders yapacağını belirtmiştir. Öğretmen adayı özellikle konunun soru çözümü kısmında bu uygulamayı yapabileceğini;

"Kullanmayı düşünürüm ama bunu önce kendim çok iyi ögrenmem lazım sonra karşımdaki insanlara anlatmam lazım. Bir de haftada 4 saatim varsa bir sınıfta dörtte dört bu uygulamayl yapmam. Uygulama yapar soru çözdürürüm.”

sözleri ile ifade etmiştir.

Öğretmen adayı $B_{1}$ öğretmenlik yaşamında dinamik ortamlarda ders yapacağını ve uygulamanın hem öğretmen hem de öğrenci açısından faydalı olacağını belirtmiştir. $\mathrm{B}_{1}$;

"Ben de tabiki kullanmayı düşünüyorum. Çünkü hem ögretmen açısından hem de ögrenci açısından çok yararlı bir program. Görsel olarak anlama ve soruları farklı yönlerden düşünme açısından çok yararlı." sözleri ile düşüncesini belirtmiştir.

Öğretmen adaylarından $B_{7}$ ise öğretmenlik yaşamında dinamik ortamlarda ders yapmayı öğrencilerinin kararlarına bırakacağını belirterek şunları söylemiştir;

“Öğretmen olduğumda bu uygulamayı yapıp yapmamayı ögrencilerime bırakırım. Ĕ̆er ögrencilerim bu programı kullanmaya olumlu baklyorsa ben de kullanırım. Ĕ̆er kullanmamay istiyorlarsa kullanmam."

Öğretmen adaylarının, dinamik yazılımın kullanımıyla oluşturulan öğrenme ortamında geometri öğrenmeye karşı ilgili oldukları görülmektedir. Yapılan derslerde öğretmen adaylarının çalışma yapraklarındaki yönergeleri takip ederek genellemelere ulaşabildikleri gözlemlenmiştir. Buna göre öğretmen adaylarının çemberin analitik incelenmesinin öğrenme ve öğretme boyutlarını, görselleştirme ve öğrencinin dikkatini toplaması ile birlikte düşünme becerilerini geliştirme ve bu sayede kalıcı ve kısa sürede öğrenme açısından değerlendirmeleri dinamik ortamda kendi öğrenmeleriyle elde ettikleri bir sonuç olarak görülmektedir.

\section{Sonuç ve Tartışma}

Araştırma probleminin deneysel bulguları 1şığında elde edilen sonuçlara göre; çemberin analitik incelenmesinin öğretiminde, dinamik ortamda eğitim görmüş öğretmen adaylarının başarı puanlarında işlem öncesi ve sonrası bakımından anlamlı bir farklılık oluşmuştur. Elde edilen bu sonuç dinamik ortamda yapılan geometri öğretimin öğretmen adaylarının başarılarını artırdığı yönünde yorumlanabilir. Araştırmadan elde edilen sonuçlar bilgisayarın 
geometri öğretiminde kullanılmasının öğrenci başarılarını artırdığı yönünde olmasından dolayı alan yazında yapılan çeşitli araştırmaların sonuçlarıyla örtüşmektedir (Baki \& Özpınar, 2007; Egelioğlu, 2008; Olkun \& Altun, 2003; Turgut \& Y1lmaz, 2010). Araştırmalar dinamik yazılımlar kullanılarak yapılan geometri öğretiminin öğrenci başarılarını olumlu etkilediğini göstermektedir (Almeqdadi, 2005; Erbas \& Yenmez, 2011; Fahlberg-Stojanovska \& Trifunov, 2010; Güven \& Kösa, 2008; Selçik \& Bilgici, 2011; Yazlık, 2011).

Araştırma probleminin nitel bulguları 1şığında elde edilen sonuçlara göre; öğretmen adaylarının çemberin analitik incelenmesinin öğretiminin dinamik ortamda yapılmasına ilişkin görüşleri içerik, öğrenme ve öğretim kategorileri altında incelenmiştir. Buna göre öğretmen adaylarının içerik kategorisi altında en fazla; dinamikliğin; kuvvet noktasının ve çember üzerindeki noktaların anlaşılmasını sağladığı üzerinde durdukları görülmüştür. Ayrıca öğretmen adayları açıların gerçek değerlerinde gözüktüğünü, çembere ait kavramların algılandığını ve çember üzerinde nokta ve doğruların ilişkisinin anlaşıldı̆̆ı üzerinde durmuşlardır. Öğretmen adaylarının öğrenme kategorisi altında en fazla, düşünme becerilerini geliştirme, görsellik, kalıcı öğrenme, kısa sürede öğrenme ve somutlaştırma üzerinde durdukları görülmüştür. Benzer sonuçlar öğretmen adaylarının matematik öğrenme ve öğretmede bilgisayar kullanımı hakkındaki görüşlerini inceleyen bazı araştırmalarda da elde edilmiştir (Baki, 2000; Corbalan, Paas, \& Cuypers, 2010; Jassó, 2004; Karatas, 2011; Kutluca \& Birgin, 2007; Olkun, Sinoplu, \& Deryakulu, 2005; Usluel \& Umay, 2005; Yıldırım, 2011; Yıldız, Baltacı, \& Aktümen, 2012). Öğretmen adayları öğretim kategorisi altında ise en fazla, öğrencinin dikkatini toplaması üzerinde durmuşlardır.

Öğretmen adaylarının öğrenim gördükleri liselerde matematik ve geometri derslerinde teknoloji kullanılıp kullanılmadığına ilişkin soruya verdikleri yanıtlar incelendiğinde matematik ve geometri derslerinde teknoloji kullanımının az olduğu; soru çözümü ve şekillerin görselleştirilmesinde kullanıldığı, dinamik bir öğrenme ortamı sağlanmadığını ifade ettikleri görülmektedir. Elde edilen bu bulguya paralel olarak Ertem (1999) okullarda matematik öğretiminde bilgisayar ve teknoloji kullanımının çok az olduğunu belirlemiştir.

Araştırmada ayrıca, öğretmen adaylarının öğretmenlik yaşamlarında dinamik ortamlarda geometri öğretimi yapmak istedikleri belirlenmiştir. Öğretmen adayları bilgisayar ile farklı örnekler çözebileceklerini ve bir sorunun farklı çözümlerini gösterebileceklerini belirtmişlerdir. Ertem (1999) araştırmasında öğretmen ve öğrencilerin bilgisayarda problem çözme, grafik çizme ve çeşitli araştırmalar ile matematik öğretiminin daha çekici hale 
getireceğine inandıklarını belirlemiştir. Buna göre; liselerde dinamik ortamların oluşturulması, öğretmenlerin derslerini bu dinamik ortamlarda sürdürmesi ve çeşitli geometri konularında dinamik öğretim materyallerinin geliştirilmesi önerilebilir.

\section{Kaynakça}

Almeqdadi, F. (2005). The effect of using The Geometer's Sketchpad (GSP) on Jordanian students' understanding some geometrical concepts. International Journal for Mathematics Teaching and Learning, (May 4). [Online]: http://www.cimt.plymouth.ac.uk/journal/mainali.pdf

Altun, M. (2002). İlkögretim 2. Kademede (6., 7., 8., sinıflarda) Matematik öğretimi. Bursa: Erkam Matbaas1.

Baki, A. (2000). Preparing student teachers to use computers in mathematics classrooms through a long-term pre-service course in Turkey. Journal of Information Techology for Teacher Education, 9(3), 343-362.

Baki, A. (2006). Kuramdan uygulamaya matematik ĕgitimi. Trabzon: Derya Kitabevi.

Baki, A. \& Özpınar, İ. (2007). Logo destekli geometri öğretimi materyalinin öğrencilerin akademik başarılarına etkileri ve öğrencilerin uygulama ile ilgili görüşleri. Mersin Üniversitesi Eğitim Fakültesi Dergisi, 153-163.

Biza, I. \& Zachariades, T. (2008). Using Dynamic geometry to introduce calculus concepts: CalGeo and the case of derivative. Research in Mathematics Education, 10(1), 89-90.

Bretscher, N. (2009). Dynamic geometry software: The teacher's role in facilitating instrumental genesis. Research in Mathematics Education, 11(2), 187-188.

Büyüköztürk, Ş. Çakmak, E. K. Akgün, Ö. E. Karadeniz, Ş. \& Demirel, F. (2010). Bilimsel araştırma yöntemleri. Ankara: Pegem Yayınları.

Carter, J. \& Ferrucci, B. (2009). Using GeoGebra to enhance prospective elementary school teachers' understanding of geometry. The Electronic Journal of Mathematics and Technology, 3(2). ISSN 1933-2823.

Corbalan, G. Paas, F. \& Cuypers, H. (2010). Computer-based feedback in linear algebra: Effects on transfer performance and motivation. Computers \& Education, 55(2), $692-$ 703.

Creswell, J. W. (2011). Educational research: Planning, conducting, and evaluating quantitative and qualitative research (4th ed.). Baston: Pearson. 
Çetin, Ö. F. Dane, A. \& Bekdemir, M. (2012). Yığılma noktası kavramı ve kullanımı. Necatibey Ĕgitim Fakültesi Elektronik Fen ve Matematik Ĕ̆itimi Dergisi (EFMED), $6(2), 217-233$.

Develi, M. H. \& Orbay, K. (2003). İlköğretimde niçin ve nasıl bir geometri öğretimi. Milli Ĕ̈itim Dergisi, 157.

Egelioğlu, H. C. (2008). Dönüşüm geometrisi ve dörtgensel bölgelerin alanlarının bilgisayar destekli öğretilmesinin başarıya ve epistemolojik inanca etkisi. Yayınlanmamış yüksek lisans tezi. Marmara Üniversitesi, Eğitim Bilimleri Enstitüsü, İstanbul.

Erbas, A. K. \& Yenmez, A. A. (2011). The effect of inquiry-based explorations in a dynamic geometry environment on sixth grade students' achievements in polygons. Computers \& Education, 57, 2462-2475.

Ertem, S. (1999). Matematik ögrretimi üzerinde bilgisayar ve teknolojinin kullanımı üzerine bir inceleme. Yayınlanmamış yüksek lisans tezi. Dokuz Eylül Üniversitesi, Eğitim Bilimleri Enstitüsü, İzmir.

Fahlberg-Stojanovska, L., \& Trifunov, Z. (2010). Constructing and exploring triangles with GeoGebra. Annals. Computer Science Series (Anale. Seria Informatică), 8(2), 45-54.

Freixas, M. Joan-Arinyo, R. \& Soto-Riera, A. (2010). A constraint-based dynamic geometry system. Computer-Aided Design, 42, 151-161.

Gardiner, J. Hudson, B. \& Povey, H. (2000). Aspects of construction and proof in a handheld dynamic geometry environment. Research in Mathematics Education, 2(1), 125136.

Güven, B. \& Karataş, İ. (2003). Dinamik geometri yazılımı Cabri ile geometri öğrenme: Öğrenci görüşleri. The Turkish Online Journal of Educational Technology, 2(2), 67-78.

Güven, B. \& Karataş, İ. (2005). Dinamik geometri yazılımı Cabri ile Oluşturmacı öğrenme ortamı tasarımı: Bir model. İlkögretim Online, 4(1), 62-72.

Güven, B. \& Kösa, T. (2008). The effect of dynamic geometry software on student mathematics teachers' spatial visualization skills. The Turkish Online Journal of Educational Technology, 7(4), 100-107.

Hangül, T. \& Üzel, D. (2010). Bilgisayar destekli öğretimin (BDÖ) 8. sinıf matematik öğretiminde öğrenci tutumuna etkisi ve bdö hakkında öğrenci görüşleri. Necatibey Eğitim Fakültesi Elektronik Fen ve Matematik Eğitimi Dergisi (EFMED), 4(2), 154176. 
Hohenwarter, M. \& Fuchs, K. (2004). Combination of dynamic geometry, algebra and calculus in the software system GeoGebra. Computer Algebra Systems and Dynamic Geometry Systems in Mathematics Teaching Conference 2004. Pecs1, Hungary.

Hohenwarter, M. Hohenwarter, J. Kreis, Y. \& Lavicza, Z. (2008). Teaching and learning calculus with free dynamic mathematics Software GeoGebra. Proceeding of International Conference in Mathematics Education 2008, Monterrey, Mexico.

Ismail, M., A. (2009). GeoGebra in Egypt. Mathematics, Statistics, Operation Research Connections, 9(2), 31-32.

Jassó, J. (2004). Teacher training with Cabri Géomètre. International Journal for Mathematics Teaching and Learning, (October 12). [Online]: http://www.cimt.plymouth.ac.uk/journal/mainali.pdf

Kalaycı, Ş. (Edt.) (2010). SPSS uygulamalı çok değişkenli istatistik teknikleri (5. Baskı). Ankara: Asil Yayın Dağıtım.

Karatas, I. (2011). Experiences of student mathematics teachers in computer based mathematics learning environment. International Journal for Mathematics Teaching and Learning, (March 10). [Online]: http://www.cimt.plymouth.ac.uk/journal/mainali.pdf

Kokol-Voljc, V. (2007).Use of mathematical software in pre-service teacher training: The case of dgs. Proceedings of British Society for Research into Learning Mathematics, 27(3), 55-60.

Kösa, T. \& Karakuş, F. (2010). Using Dynamic geometry software Cabri 3D for teaching analytic geometry. Procedia Social and Behavioral Sciences 2. (1385-1389). İstanbul: World Conference on Educational Sciences (WCES-2010).

Köse, N. Y. \& Özdaş, A. (2009). İlköğretim 5. sınıf öğrencileri geometrik şekillerdeki simetri doğrularını Cabri geometri yazılımı yardımıyla nasıl belirliyorlar? Illkögretim Online, $8(1), 159-175$.

Kutluca, T. \& Birgin, O. (2007). Doğru Denklemi Konusunda Geliştirilen Bilgisayar Destekli Öğretim Materyali Hakkında Matematik Öğretmeni Adaylarının Görüşlerinin Değerlendirilmesi. Gazi Eğitim Fakültesi Dergisi, 27(2), 81-97.

Lopez-Real, F. \& Leung, A. (2006). Dragging as a conceptual tool in dynamic geometry environments. International Journal of Mathematical Education in Science and Technology, 37(6), 665-679. 
Mainali, B. R. \& Key, M. B. (2012). Using dynamic geometry software GeoGebra in developing countries: A case study of impressions of mathematics teachers in Nepal. International Journal for Mathematics Teaching and Learning, (April 12). [Online]: http://www.cimt.plymouth.ac.uk/journal/mainali.pdf

McMillan, J. H. \& Schumacher, S. (2010). Research in education: Evidence-based inquiry (7th ed.). Boston: Pearson.

National Council of Teachers of Mathematics (NCTM). (2000). Principles and standards for school mathematics. Reston, VA20191-9988.

Olivero, F. (2001). Conjecturing in open geometricsituations using dynamic geometry: an exploratory classroom experıment. Research in Mathematics Education, 3(1), 229-246.

Olkun, S. \& Altun, A. (2003). İlköğretim öğrencilerinin bilgisayar deneyimleri ile uzamsal düşünme ve geometri başarıları arasındaki ilişki. The Turkish Online Journal of Educational Technology, 2(4), 86-91.

Olkun, S. Sinoplu, N. B. \& Deryakulu, D. (2005). Geometric Explorations with Dynamic Geometry Applications based on van Hiele Levels. . International Journal for Mathematics Teaching and Learning, (April 13). [Online]: http://www.cimt.plymouth.ac.uk/journal/mainali.pdf

Oral, B. \& İlhan, M. (2012). İlköğretim ve lise matematik öğretmen adaylarının geometrik düşünme düzeylerinin çeşitli değişkenler açısından incelenmesi. Necatibey Eğitim Fakültesi Elektronik Fen ve Matematik Eğitimi Dergisi (EFMED), 6(1), 201-219.

Özdemir, A. Ş. \& Tabuk, M. (2004). İlköğretim 7.sınıflarında “Çember, Daire ve silindir” konusunun öğretiminde bilgisayar destekli öğretimin başarıya etkisi. Abant İzzet Baysal Üniversitesi Eğitim Fakültesi Dergisi, 7 (4), 41-52.

Selçik, N. \& Bilgici, G. (2011). GeoGebra yazılımının öğrenci başarısına etkisi. Kastamonu Ĕ̆itim Dergisi, 19(3), 913-924.

Sinclair, N. \& Yurita, V. (2008). To be or to become: How dynamic geometry changes discourse. Research in Mathematics Education, 10(2), 135-150.

Tatar, E. Akkaya, A. \& Kağızmanlı, T. B. (2011). İlköğretim matematik öğretmeni adaylarının geogebra ile oluşturdukları materyallerin ve dinamik matematik yazılımı hakkındaki görüşlerinin analizi. Turkish Journal of Computer and Mathematics Education, 2(3), 181-197.

Turgut, M. \& Y1lmaz, S. (2010). Teknoloji destekli lineer cebir öğretiminin öğrencilerin geometrik düşünme düzeylerine etkisi. E-Journal of New World Sciences Academy, 5(3), 702-712. 
Ubuz, B. (1999). 10. ve 11. sınıf öğrencilerinin temel geometri konularındaki hataları ve kavram yanılgıları. Hacettepe Üniversitesi Ĕ̈itim Fakültesi Dergisi, 16-17, 95 - 104.

Usluel, Y. K. \& Umay, A. (2005). İlköğretim Matematik Öğretmen Adaylarının Öğretimde BİT Kullanımına Bakışı: Boylamsal Bir Çalışma. Eurasian Journal of Educational Research, 19, 102-111.

Wares, A. (2010). Using dynamic geometry to explore non-traditional theorems. International Journal of Mathematical Education in Science and Technology, 41(3), 351-358.

Yazlık, D. Ö. (2011). İlköğretim 7. sinıflarda Cabri geometri plus u ile dönüşüm geometrisi ögrretimi. Yayınlanmamış yüksek lisans tezi. Selçuk Üniversitesi, Eğitim Bilimleri Enstitüsü, Konya.

Yıldırım, A. \& Şimşek, H. (2011). Sosyal bilimlerde nitel araştırma yöntemleri (8. Baskı). Ankara: Seçkin Yayıncılık.

Yıldırım, İ. (2011). Teknoloji destekli matematik ögretimi çerçevesinde alternatif ölçme araçlarının kullanımı. Yayınlanmamış yüksek lisans tezi. Gaziantep Üniversitesi, Sosyal Bilimler Enstitüsü, Gaziantep.

Yıldız, A. Baltacı, S. \& Aktümen, M. (2012). İlköğretim matematik öğretmen adaylarının dinamik matematik yazılımı ile üç boyutlu cisim problemlerini çözme süreçleri. Kastamonu Ĕ̈itim Dergisi, 20(2), 592-604. 
Ek 1. Başarı Testi

Ad1- Soyad1:

1. Merkezi, $y=2 x+2$ doğrusu üzerinde bulunan ve 3. bölgede eksenlere teğet olan çemberin denklemini bulunuz.

2. $\mathrm{A}(2,4)$ ve $\mathrm{B}(-1,2)$ noktalarından geçen ve merkezi, $\mathrm{x}$ ekseni üzerinde bulunan çemberin denklemini yazınız.

3. $(x-4)^{2}+(y-5)^{2}=25$ denklemiyle verilen çemberin $A(1,9)$ noktasından geçen teğetinin denklemini bulunuz.

4. $\mathrm{P}(4,2)$ noktasından, denklemi $\mathrm{x}^{2}+\mathrm{y}^{2}=10$ olan çembere çizilen teğetlerin denklemlerini yazınız.

5. $3 x+4 y-1=0$ denklemiyle verilen doğruya teğet ve merkezi $M(4,6)$ olan çemberin denklemini yazınız.

6. Denklemi $y=x+3$ olan doğru ile denklemi $x^{2}+y^{2}=5$ olan çemberin birbirine göre konumunu belirleyiniz.

7. $A(-3,2)$ noktasının, $(x-2)^{2}+(y+1)^{2}=7$ denklemi ile verilen çembere göre kuvvetini bulunuz.

8. $\mathrm{P}(-1,2)$ noktasından, denklemi $(x-1)^{2}+(y+2)^{2}=8$ olan çembere çizilen teğet parçasının uzunluğunu bulunuz.

9. Denklemleri $(x-2)^{2}+(y-1)^{2}=1$ ve $(x+4)^{2}+(y-7)^{2}=6$ olan çemberlerin birbirine göre konumunu belirleyiniz.

Ek 2. Yarı-Yapılandırılmış Odak Grup Görüşme Soruları

1. Çemberin analitiğinin dinamik öğretimi hakkında ne düşünüyorsunuz?

2. Öğretmen olduğunuzda dinamik bir ortamda geometri öğretimi yapmayı düşünür müsünüz? Neden? 
Ek 3. Araştırmada Kullanılan Dinamik Materyallerin Görüntüleri

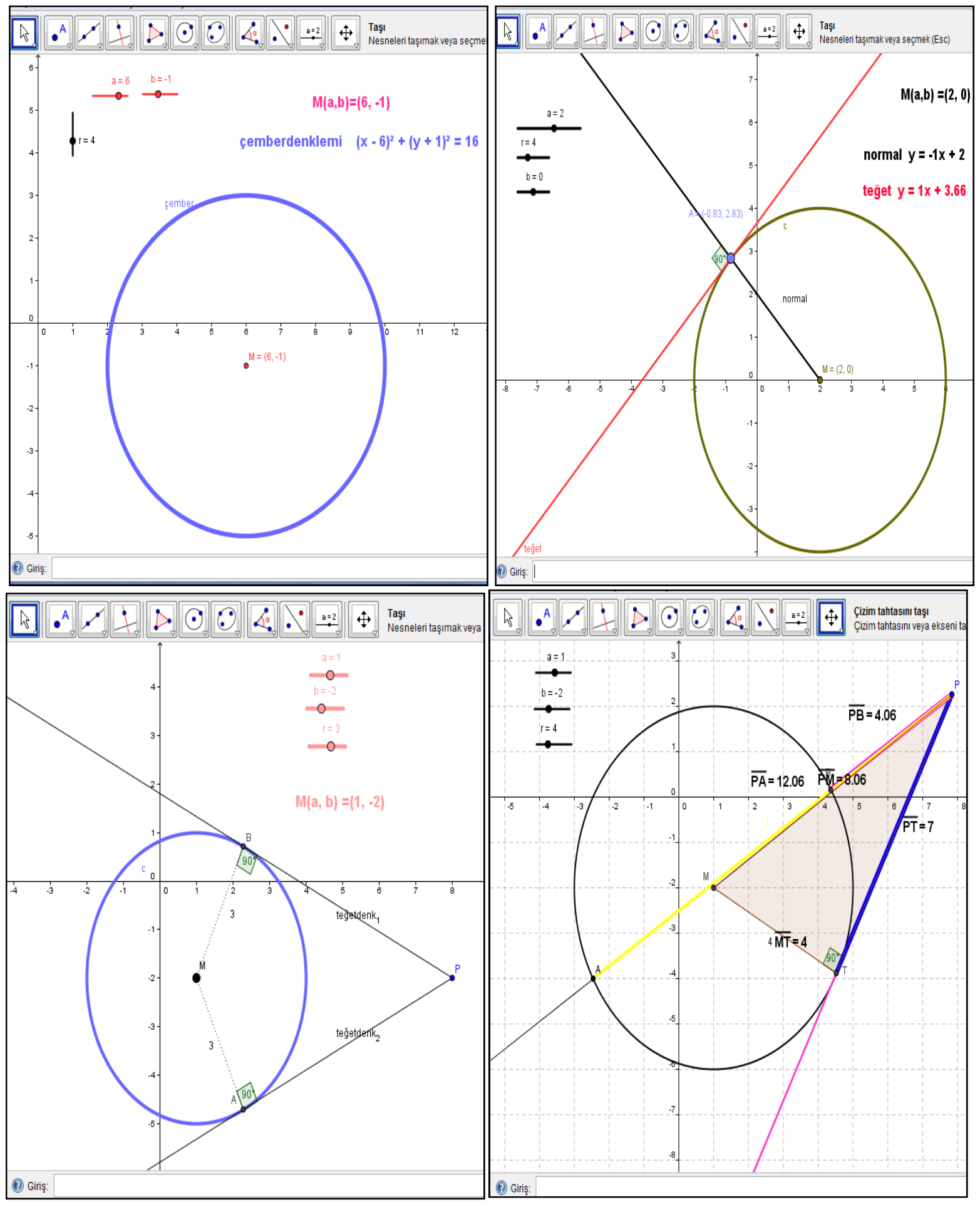


Ek 4. Araştırmada Kullanılan Çalışma Yaprakları

\section{ÇALIŞMA YAPRAĞI -1-}

“çember_1.ggb” dosyasını açınız. a, b ve r sürgülerini aşağıda verilen değerleri alacak şekilde sürükleyin. Sürgülerin aldığı bu değerlerle oluşan çemberlerin denklemlerini verilen tabloda yazınız.

\begin{tabular}{ccc}
\hline$M(a, b)$ & $r$ & Çember Denklemi \\
\hline$(1,2)$ & 3 & \\
\hline$(2,-3)$ & 1 & \\
\hline$(-1,4)$ & 2 \\
\hline$(4,0)$ & 5 \\
\hline$(0,3)$ & 4 \\
\hline$(-1,-4)$ & 6
\end{tabular}

r yarıçaplı, M(a, b) merkezli çember denklemi için bir genelleme yapabilir misiniz?

\section{ÇALIŞMA YAPRAĞI -3-}

“çember_3.ggb" dosyasını açınız. a, b ve r sürgülerini ve çember üzerinde alınan A noktasını aşağıda verilen değerleri alacak şekilde sürükleyin. Bu değerlerle oluşan çemberlerin, teğet ve normal denklemlerini verilen tabloda yazınız.

\begin{tabular}{|c|c|c|c|c|}
\hline $\mathbf{M}(\mathbf{a}, \mathbf{b})$ & $\mathbf{r}$ & $\mathbf{A}$ & Teğet Denklemi & Normal Denklemi \\
\hline$(\mathbf{0}, \mathbf{0})$ & 5 & $(-4,3)$ & & \\
\hline$(4,5)$ & 5 & $(1,9)$ & & \\
\hline$(2,-3)$ & 2 & $(4,-3)$ & & \\
\hline$(-6,8)$ & 2 & $(-2,2)$ & & \\
\hline$(1,2)$ & 5 & $(5,-1)$ & & \\
\hline$(4,-1)$ & 7 & $(-1,4)$ & & \\
\hline
\end{tabular}

A noktasını sürüklediğinizde teğet ve normal doğrularının denklemleri neden değişmektedir? 


\section{ÇALIŞMA YAPRAĞI -4-}

"çember_4.ggb" dosyasını açınız. a, b ve r sürgülerini ve çember dışında alınan P noktasını aşağıda verilen değerleri alacak şekilde sürükleyin. Bu değerlerle oluşan çemberlerin teğet denklemlerini verilen tabloda yazınız.

\begin{tabular}{ccccc}
\hline$M(a, b)$ & $r$ & $P$ & Teğet Denklemi_1 & Teğet Denklemi_2 \\
\hline$(0,0)$ & 1 & $(4,2)$ & & \\
$(1,-2)$ & 3 & $(8,-2)$ & \\
& & & \\
\hline
\end{tabular}

\section{ÇALIŞMA YAPRAĞI -7-}

“çember_7.ggb" dosyasını açınız. a, b ve r sürgülerini ve bir P noktasını aşağıda verilen değerleri alacak şekilde sürükleyin. $\mathrm{k}=\mathrm{PTTl}^{2}, \mathrm{P}$ noktasının çembere göre kuvvetini oluşturduğuna göre, istenilen değerleri verilen tabloda yazınız.

\begin{tabular}{cccc}
\hline$M(a, b)$ & $\mathbf{r}$ & $\mathbf{P}$ & $\mathrm{k}=I \mathbf{P T I}^{2}$ \\
\hline$(1,-2)$ & 4 & $(2,3)$ & \\
$(2,0)$ & 4 & $(8,-1)$ & \\
$(1,-1)$ & 2 & $(2,-1)$ & \\
$(1,4)$ & 5 & $(2,5)$ & \\
\hline
\end{tabular}

1. P noktası çemberin dışında olduğunda noktanın çembere göre kuvveti hangi aralıkta değerler alır? Bir genellemeye varabilir misiniz?

2. P noktası çemberin üzerinde olduğunda noktanın çembere göre kuvveti hangi aralıkta değerler alır? Bir genellemeye varabilir misiniz?

3. P noktası çemberin içinde olduğunda noktanın çembere göre kuvveti hangi aralıkta değerler alır? Bir genellemeye varabilir misiniz? 